\title{
Styles of Thought on the Continental Drift Debate
}

\author{
Pablo A. Pellegrini ${ }^{1}$ \\ Published online: 4 February 2019 \\ (C) The Author(s) 2019
}

\begin{abstract}
The continental drift controversy has been deeply analysed in terms of rationalist notions, which seem to find there a unique topic to describe the weight of evidence for reaching consensus. In that sense, many authors suggest that Alfred Wegener's theory of the original supercontinent Pangea and the subsequent continental displacements finally reached a consensus when irrefutable evidence became available. Therefore, rationalist approaches suggest that evidence can be enough by itself to close scientific controversies. In this article I analyse continental drift debates from a different perspective which is based on styles of thought. I'll argue that continental drift debate took much longer than it was usually recognized with two styles of thought coexisting for hundreds of years. These were fixism and mobilism and they were always confronting their own evidence and interpretations and functioning as general frameworks for the acceptability of a specific theory. Therefore, this text aims to bring much broader sociological elements than usually involved in the analysis of the continental drift theory.
\end{abstract}

Keywords Scientific controversies - Styles of thought - Continental drift · Wegener · Pangea $\cdot$ Evidence

\section{Introduction}

According to the usual story about the continental drift theory, in 1912 Alfred Wegener argued that all continents had once been united before splitting apart. He is considered to have been far ahead of his time because his assumptions turned to be right but they lacked enough evidence. At the beginning, a few scientists supported him, but most geologists simply rejected his theory. Later on, in the 1960s new evidence from paleomagnetism was presented and, with this new evidence, the geologists' community finally accepted Wegener's continental drift theory.

That is a brief version of the story, for sure. There are also exhaustive, well documented and rigorous versions of it, like the book published by Oreskes (1999) or the four volumes

Pablo A. Pellegrini

ppellegrini@unq.edu.ar

1 CONICET - Instituto de Estudios sobre la Ciencia y la Tecnología, Universidad Nacional de Quilmes / Max Planck Institute for the History of Science, Roque Sáenz Peña 352, Bernal, B1876BXD Buenos Aires, Argentina 
written by Frankel (2012). In any case, the story is thrilling because it reflects a community of scientists who, since 1912, had the theory within their grasp but resisted to accept it for more than 50 years, until they surrendered to the final evidence.

All stories about continental drift begin with Wegener in 1912, and the heart of the conflict is situated on the difficulties of the scientific community to accept his theory. Here, some subtle divergences can be found among authors. Some emphasize the figure of Wegener, pointing out his remarkable intuition to develop a correct theory without much evidence. This is a way of explaining why Wegener's theory did not have many supporters. In other words, scientists who lacked his intuition would not get convinced by his modest evidence. Indeed, Wegener has been described as "an early advocate of an immature theory" (Oreskes 2013, 29) or "born at the wrong time" (Nield 2015, 193). In explaining the above, Hallam reaches the conclusion that "when discoveries are made before their time, they are almost certain to be ignored or meet with opposition which is too strong to overcome" (Hallam 1983, 152). In that sense, it has been also argued that: "The theory remained controversial for nearly half a century [...] [and] the reason for this was that the scientific community had difficulty testing the hypothesis rigorously with available techniques and also lacked a convincing explanatory mechanism" (Giller et al. 2004, 268).

Other authors emphasize the rejection attitude from the rest of the community, mostly noticing that main opponents were American geologists and, thereby, explaining the rejection in terms of the "American chauvinism and recalcitrance" (Newman 1995, 79). ${ }^{1}$ Oreskes's work is subtler in explaining that American geologists had standards of practice that diverged from European geologists'. According to Oreskes, American geologists tried to elucidate Earth history through the physical evidence observed, while Europeans tried to understand Earth history in terms of the physics and chemistry laws (Oreskes 1999). In similar terms, Greene argues that there were two different approaches: those like Wegener who mainly rendered importance to the plausibility of a theory and its consonance with the laws of nature, while for the Anglo-American school the idea that it was necessary to demonstrate de existence of something beyond its plausibility prevailed (Greene 2015, 262).

The story reaches its resolution when new paleomagnetism evidence is found in the 1960s. This new evidence is presented as the key that dissolved all possible opposition: "They [sc. the opponents] only later changed their views when the evidence, especially from marine geologists, became irrefutable" (Giller et al. 2004, 268). ${ }^{2}$ That evidence, it is argued, came to forge the final consensus.

Rationalist perspectives, as defined here, "favors internal understandings of what knowledge is" (Hacking 1999, 91-92), assumes "universal, context-independent criteria of truth and rationality" (Barnes and Bloor 1982, 35), and for whom "lack of information is the primary obstacle to conclusive, prompt determinations" (Nelson 1994, 536). Away from these perspectives, since the end of 1970s, sociology of scientific knowledge has been arguing that disputes between scientists cannot be socially explained in terms of what is true, rational, successful or progressive. This kind of ex post judgement of knowledge ignores the role of social aspects involved in its stabilization (Bloor 1976; Collins 1981). Experiments and observation are

\footnotetext{
1 Rupke adds another possible contributory factor to this argument: Eurocentric continentalism in continental drift theory may have played a role in causing the American distaste for Wegener's theory (Rupke 1996, 268).

2 Similar expressions can be found in other authors: "the arguments for continental motions did not gel until the 1960s, when a drastic expansion of geophysical research, driven by the cold war, produced evidence that reopened and eventually settled the debate" (Oreskes 2013, 27). See also Giere (1988), Thagard (1992), and Laudan and Laudan (1989).
} 
always ambiguous, so closure of controversies is not just a matter of unequivocal evidence but a process of social agreements between experts (Collins and Pinch 1998, 145-146). Somehow, the usual continental drift tale seems to point somewhere else: the final evidence stabilized geological knowledge and put everyone in his place, in agreement with rationalist perspectives. The narratives around continental drift controversy conclude that with scarce evidence truth is hard to see; but, when irrefutable evidence becomes available, consensus is reached. In the end, with the help of evidence, prejudices fall and truth prevails.

It's a nice tale about the triumph of rationality and the weight of evidence. But, there are some important issues about the controversy that these rationalist approaches overlook. On the one hand, evidence actually weighs less for scientists than those approaches consider. On the other hand, the social acceptance of a theory can be a long and complex process even for scientists, as it happened with previous theories very similar to Wegener's which also had many difficulties to be taken seriously by the dominant thinking style.

The majority of philosophers and historians of science seems to analyse this case in terms of a mainly rationalistic account of progress of science (e.g. Le Grand and Homer 1988; Frankel 1979; Laudan 1987; Šěelja and Weber 2012). Fewer and forgotten seem those who intended to view this episode as a conflict of paradigms (e.g. Stewart 1990).

The main objective of this article is to offer a different approach towards understanding the conflict around the acceptance of the continental drift theory, less grounded on rational explanations about the inherent weight of evidence and more concerned about the cultural and social contexts that shaped this debate. It is important to advise that this does not imply to reject the role of evidence in the acceptance of the plate tectonic theory, but to focus on its social and cultural backgrounds. I do not pretend to argue that evidence has no role; rather, I criticise perspectives that only focus on evidence while explaining the social acceptance of the theory since such explanation tends to conceive the scientific community as a purely logical organism. On the contrary, I am highlighting the importance of broader cultural frameworks.

I will argue that continental drift debate took much longer than it is usually recognized and, although evidence was always central in the discussion, the cultural patterns which shaped the debate become crucial elements when considering the acceptance of theories. Therefore, the continental drift debate can be analysed as grounded on two distinct "styles of thought": fixism and mobilism. For hundreds of years, those patterns of thinking have been struggling around how to understand the Earth and the changes on it. The main approaches were either creation followed by degradation or in constant evolution. Consequently, continental drift theories were anchored and shaped by the fate of those styles of thought. Along the history of this debate, fixists used evidence and interpretations which supported the position that continents had been essentially stable over time; while mobilists used to reason in terms of dynamic elements able to move and evolve, conceiving continents as once united and afterwards drifted apart. The preferences of the scientific community towards a particular theory within this debate are not disassociated from the prevalent style of thought.

Maybe much of the rationalist moral of the tale would vanish when analysing the continental drift debate by focusing on styles of thought approach, but questions about what convinces people in controversial issues turns this debate even more thrilling.

\section{Continental Drift Theory and Its Many Discoverers}

This section will summarize the continental drift theories, showing a long neglected tradition including Wegener's work. 
Alfred Wegener is usually referred to as far ahead of his time by being the first scientist to present the correct theory of continental displacement although he lacked enough evidence. In a certain way, to present Wegener's theory as completely new and ahead of his time serves as an explanation for its rejection. That is, it was the fear of a new perspective what compelled scientists to remain clinging to their usual explanations. But, as it will be shown, if the theory of continental drift had many precedents before Wegener's, the explanation of its long lasting rejection must be found elsewhere.

Wegener argued that during the carboniferous period all continents were united in what he called "Pangea", a supercontinent. ${ }^{3}$ Afterwards, during the cretaceous period, Pangea began to break apart. The American continent began to drift away from Europe and Africa; while Asia separated from the Antarctica and South Africa by rotating counter-clockwise. During the following periods, continents continued to drift away from one another causing the separation of Australia from Antarctica, for example. In this way, Wegener intended to explain the origins of continents and oceans ${ }^{4}$ in reference to the horizontal displacement of the continental masses.

He provided evidence supporting his theory. He argued that the continents margins matched and, therefore, they should have once been united and then split apart. He also considered the distribution of similar fossils and current flora and fauna, which-although some existing differences-also showed similarities in different continents. This allowed him to state that "what is today a genus or family was once a species in prehistoric times" and, therefore, there must have been exchanges that could only have taken place if lands had been connected (Wegener 1929, 6). The several geological structural similarities among the continents as well as the coastline location of mountain ranges supported Wegener's Pangea hypothesis. In short, the three main bodies of evidence he presented were related to: the shape of the continents; the similarities in fauna and flora; and geological connections. ${ }^{5}$ Those groups of evidence were used by Wegener to support his theory that the continents had once been together in what he called Pangea and then, they drifted apart.

In his own writings, Wegener conveys the impact caused by noticing the complementarity of the Atlantic coastline on a map in 1910 (Hallam 1975, 90). Then, he carried out a series of readings that influenced his ideas even more. According to Greene $(2015,242)$, in Wegener's Germany, senior scientists usually devoted the last years of their careers to write books synthesizing the existing materials in their fields of study. In that sense, Wegener had the chance to read synthetic works of geology, oceanography and geophysics which indeed provided arguments to his theory. In particular, in a few books, Wegener incorporated the ideas and evidence which had been present in hundreds of papers published in previous years (Greene 2015, 242-247). Those books were: The face of the Earth by the

\footnotetext{
3 The term "Pangea" or "Pangaea", would have been chosen by Wegener because of its Greek roots meaning "all land" (Miller 1983, 48).

4 Such was the title of his book.

5 Another sort of evidence brought forward by Wegener came from palaeoclimatology, as he argued that the drastic changes of the climates linked to the shift of the continents relative to the poles (Le Grand and Homer 1988, 44). Oreskes summarizes the evidence that Wegener brought up through the following issues: paleontological parallels suggesting extensive interchange of fossil species between continents during certain geological periods; stratigraphic parallels suggesting prior physical proximity of the continents; geological indicators of paleoclimatic change; the jigsaw-puzzle fit of the continents; longitudinal measurements from the Danish Greenland expeditions, which indicated a present-day westward displacement of Greenland (Oreskes 1999, 273-275).
} 
Austrian geologist Eduard Suess; the Handbook of oceanography by Otto Krümmel; The evolutionary development of the continents and their life-forms by Theodor Arldt; Physics of the Earth by Maurycy Rudzki, and the Textbook of general geology by Emanuel Kayser, among others. Eduard Suess, in The face of Earth, had particularly insisted geologists not to focus so much on minor details but to pay attention to the very large dislocations of Earth's crust. From these previous works, Wegener obtained his firsts ideas about the continental drift theory which he published in 1912.

The fact that in the 1960s the tectonic plate theory was accepted and, having this theory, similar ideas to those stated by Wegener in 1912, made scientific community consider him the father of the continental drift theory. However, other predecessors of the same idea can be found such as Taylor, Mantovani and Pickering. ${ }^{6}$ This could allow us to think of the continental drift theory as a simultaneous discovery. Indeed, as Merton had already pointed out, simultaneous discoveries happen so often in science that they are the rule rather than the exception (Merton 1961, 480). Some well-known examples are those of Darwin and Wallace in discovering the evolutionary theory; Newton and Leibniz in the calculus theory; Euler and Lagrange regarding the solution to the variation calculus, among others. To establish the actual discoverer of a scientific fact is indeed arbitrary since there is always previous background which may be considered valuable in contributing to the discovery. As regards this issue, in 1980 Joseph Stigler proposed that no scientific discovery is named after its original discoverer arguing that it is always possible to find out previous discoverers who have remained in the shadows, without receiving any credit for their research (Stigler 1999, 277).

The fact that the same general ideas can be found in Wegener's contemporary authors may make us think of a simultaneous discovery. It would also speak of a certain intellectual atmosphere of the era where similar ideas circulated. However, those ideas can still be found even looking back much more than a 100 years. In this case, there is something else than just a simultaneous discovery. These ideas are not only the product of some specific time but they are linked to a broader style of thought.

Indeed, before Wegener, Taylor, Mantovani and Pickering, the works of Eduard Suess's contemporary thinkers during the last decades of nineteenth century presented very similar and influential ideas. But, again, even much further back in time predecessors of these ideas can be found.

For example, in 1858, Antonio Snider-Pellegrini suggested the idea of continental drift. This French naturalist argued that there was a time when all landmass was united and after that a violent separation took place with a centrifuge force which caused the continents to drift apart (Snider-Pellegrini 1858, 304-314). He devoted several pages to explain his ideas showing the shape of the continents and the similarities of the fossils found in them as evidence. He even provided maps showing the location of the continents before and after the separation.

\footnotetext{
${ }^{6}$ A few years before Wegener, in 1909, the Italian geologist Roberto Mantovani also published his own ideas about a former supercontinent that afterwards split apart (Scalera 2003, 71-72). By the end of 1908, the American Geologist Frank Bursley Taylor argued that, on the Tertiary period, the continents had moved due to what he called "deforming forces" (Taylor 1910). In his most complete version of the continental drift theory published in 1910, Taylor provided geological evidence in support of his theory (Laudan 1985, 119). In earlier years, in fact, it was common to read about the "Taylor-Wegener hypothesis" (Lane 1944, 176; Powell 2015, 70). Another scientist working independently with the same ideas was Howard Baker, who in 1911 published his conclusions that the present continental shapes were produced as a result of a sudden separation of landmasses (Kasbeer 1973, 9-12; Du Toit 1957, 14). A couple of years before Taylor, the American astronomer William Pickering had also postulated the displacement of the continents (Pickering 1907).
} 
Before Snider-Pellegrini, in 1801, Alexander von Humboldt had noticed that South America and Africa had once belonged to the same continent due to the shape of their coasts and rock formations (Rupke 1970, 350). Furthermore, the idea that continents fit together can also be found in the 1756 work of the German theology professor Theodor Christoph Lilienthal (Rupke 1970, 349).

The list of ancient proposers of the continental drift theory also includes names as Francis Bacon, Comte de Buffon, François Placet, Thomas Young, Richard Owen, JeanBaptiste Lamarck, Heinrich Wettstein, Osmund Fisher and Charles B. Warring (Du Toit 1957; Carozzi 1970, 1983; Kasbeer 1973). Abraham Ortelius, a sixteenth century geographer, is considered the first forerunner to include two central aspects of the continental drift theory: the continental fit and the movement of landmasses (Romm 1994). In his 1596 book entitled Thesaurus geographicus, Ortelius argued that America had been "torn away from Europe and Africa, by earthquakes and flood", and that "the vestiges of the rupture reveal themselves, if someone brings forward a map of the world and considers carefully the coasts of the three aforementioned parts of the Earth, where they face each other" (cited in Romm 1994, 408).

Consequently, there has been a long tradition of authors who proposed a continental drift theory throughout the last 400 years. Of course, it has never been exactly the same theory; every author provided his own singularities about it. Some versions of the theory are more developed or detailed than others. An idea is not exactly the same through different times and for different people. However, there are general aspects shared by all of them. In the case of the continental drift theory, this shared idea is that continents were once united and afterwards they drifted apart. Each author supporting this theory provided some kind of evidence, but there were always unconvinced colleagues who rejected it.

Wegener's situation towards the continental drift theory may present certain parallelism with Mendel being credited for genes discovery. Published in 1866, Mendel's research was not given much importance until 1900 when he began to be seen as the father of genetics. This significant time gap between the first presentation of the theory and its later acceptance is often explained in biology and genetics textbooks by considering Mendel as being way ahead of his contemporaries' thought. In a much subtler analysis, Augustine Brannigan considers that Mendel was not the founder of genetics nor was his contribution overlooked. Rather, the contexts in which Mendel's work was presented as well as its significance changed substantially over time. When first appeared, Mendel's work was received as normal science with its usual experiments with hybrids. Several decades later, thanks to the influence of Darwin's theory of evolution, Mendel's work was accepted as a revolutionary theory which allowed to understand how genetic information was transmitted resulting crucial for the framework of evolution (Brannigan 1981, 90). In 1900, a scientific community of biologists deeply committed to evolution looked back at Mendel to find a revolutionary founder hero. Something similar happened with geologists and the figure of Wegener in the 1960s:

The excitement caused by the acceptance of the models of a dynamic Earth in the mid-1960s was not just that of an old theory finally becoming established, it was that 
of complete novelty. In the euphoria of discovery geologists talked and wrote of their

"scientific revolution"; in searching back for the founder of the revolution their atten-

tion focused on one man: Alfred Wegener. (Muir Wood 1980, 252)

The symbolic place of Alfred Wegener as the forefather of continental drift theory relies on the way geology as discipline constructed its own past in the 1960s. ${ }^{7}$ But even Wegener himself recognized some similarities between previous geological and geophysical approaches and findings and his theory (Greene 2015, 250-251; Georgi 1962, 310).

It is not the purpose of this work to discredit Wegener, who developed several arguments on the continental drift theory and presented it solidly showing other theories' weaknesses. In fact, as Oreskes remarks, Wegener's data were not poor (Oreskes 1999, 275). The point is that he was neglected as had been many before him with similar ideas. Of course, theories are not the same as fragmentary ideas and some of the predecessors of the continental drift theory had only provided a preliminary draft. Wegener was not the first drifter but he developed a full-fledged argumentation for it (Šešelja and Weber 2012, 148). In fact, whether as full theories or as fragmentary ideas, these proposals may become acceptable or not. The continental drift ideas which had circulated over centuries even before Wegener were also ignored by the dominant naturalists of the time and that is a relevant data. Silence can be a powerful tool in a long debate. To defy a dominant way of thinking and be taken seriously is not an easy task. Being ignored is a way of dealing with these challenges.

The first conclusion drawn from this section is that the continental drift theory is found in many different authors through almost 400 years. The second consideration, to be analysed in the following section, is that this long tradition of thought has remained confined to a minority until the 1960 s.

\section{Styles of Thought}

The existence of different styles of thought has always been at the very heart of sociology of knowledge. Indeed, in his analysis of the early nineteenth century German conservatism, Karl Mannheim described it as a particular style of thought. The notion of "styles of thought" in terms of Mannheim (1986) is oriented to the cognitive dimensions shared by a particular group. In such cognitive dimensions, the theoretical expressions of the style in texts produced by intellectuals might be found as well as their more diffuse worldview which undergirds the style (Nelson 1992, 27).

The concept of style was developed in the history of art in order to show cultural patterns, but both this concept and other related terms have also proved useful among historians and sociologists of science (Harwood 1993, 9). A "thought collective", as coined by Ludwik Fleck, refers to a community of people who have a determined thought style in common. He defined it as a tradition of shared assumptions largely invisible to members

\footnotetext{
7 Rachel Laudan argues that plate tectonic theory in the 1960s revolutionized geology redefining its boundaries. In face of those changes, historians of plate tectonics revised geologists' conception of their discipline since they felt the need for some conceptual background for their claims (Laudan 1983, 93-94). Within this redefinition of geology paradigms, it seems reasonable to think that Wegener began to be seen as a forerunner: "This is parallel and similar to the Copernican revolution and should perhaps be called the Wegenerian revolution from its chief advocate" (Wilson 1968, 317).
} 
and, thus, rarely questioned. ${ }^{8}$ Nevertheless, "the thought style may also be accompanied by a technical and literary style characteristic of the given system of knowledge" (Fleck 1979, 99); so, Fleck's term is meant to refer to more than a mere set of shared opinions (Mößner 2011, 365). In any case, the influence of a thought style on the individual's scientific work is not a conscious one and it is through education that a style of thought is inherited (Harwood 1986, 177; Mößner 2011, 364).

The crucial point, of course, is that different styles of thought may coexist, each one in each community. Each closed system of believes possesses its own validity criteria and it is defended with tenacity by its supporters (Giedymin 1986, 179).

This article focuses on the study of a historical case and, for such a purpose, I find useful the notions that Jonathan Harwood and Ian Hacking developed. Indeed, both Harwood and Hacking have argued that the concept of style can serve as a basic unit of historical analysis (Vicedo 1995, 232). But, of course, there are many theoretical approaches to the notion of style of thought that can be found in literature. ${ }^{9}$

First employed to suggest broad frameworks which impact on the way science is done, Hacking developed the notion of styles of reasoning as forms which emerge at a specific time in history and determine what counts as true or false (Hacking 1982, 65). Hacking's interest in the historical and situated conditions of possibility for the emergence of concepts and objects was influenced by Foucault and Wittgenstein (Martínez 2016; Sciortino 2016). For Hacking, once a style of reasoning is formed in a certain social context, it provides its own standards of objectivity, its own kinds of answers (Hacking 1992, 13). According to Sciortino, there is a certain epistemic relativism in Hacking's approach since the questions and the methods of verification are changeable and always relative to a given style of reasoning (Sciortino 2016, 182).

Jonathan Harwood, in his study of German genetics community, assumes styles of thought as an analytical tool which allows to shed light on different patterns of thought or practices. According to Harwood, the analysis of thought styles must find distinctive recurring elements in different groups, but also their presence in various instances of cultural activities (Harwood 1993, 9). ${ }^{10}$

\footnotetext{
${ }^{8}$ During the last decades, Ludwik Fleck's work has gained visibility. Fleck's ideas, published in German in 1935, anticipated by many years the current arguments of sociology of scientific knowledge (see Fleck 1979; Harwood 1986; Löwy 1988). The resemblance between his notions of "styles of thought" and "thought collective" and those from Kuhn's "paradigms" and "scientific communities" is remarkable. Nevertheless, a more detailed approach may find differences among them, like the notion of scientific revolution of Kuhn which does not seem to have a parallel in Fleck's work (Mößner 2011, 369).

9 Crombie (1994) distinguishes several "styles of thinking" by analysing the way arguments were deployed through the history of science in his monumental Styles of scientific thinking in the European tradition. Maienschein (1991) prefers the term "epistemic styles" to strengthen the idea that science consists of experiments as well as reasoning because she rejects the idea of using a term which focuses on theory change. Similarly, Knorr-Cetina (2007) employs the notion of "epistemic cultures" emphasizing the role of practices within cultures. Meanwhile, Nevers et al. (2001) choose to develop the notion of "types of research" which are formed by the prevailing organizational structures and processes as well as the practice of research and the interpretational framework in which they are embedded. These notions clearly overlap with each other and authors often recognize it. Nevertheless, differences exist: some authors emphasize the multiple interpretational frameworks while others highlight the practices involved, their origins or consequences.

${ }^{10}$ In that sense, Harwood describes a comprehensive and a pragmatic style of thought in German genetics. Harwood uses patterned differences as regards interests and values across several cultural sectors to define these two styles of thought (Hopwood 1994, 240). The attention to broader cultural aspects of a thought style is not exclusive to Harwood. Mary Douglas identifies cultural tendencies precisely by following a thought style across different cultural issues. Within the Durkheimian tradition, Douglas considers that "a
} 
A first general idea I would like to acknowledge as regards the use of the "style of thought" concept is that there are different ways of reasoning that may coexist in space or time. Underlying the diversity of styles of thought is the general idea that in science and knowledge there are several patterns of thinking.

The second powerful idea to be used in relation to the "style of thought" concept is that the acceptance or rejection of a scientific theory can only be understood within a broader cultural context which defines what is acceptable or not. Indeed, each style of thought possesses its own frame of validity, that is to say, its own tools to define what kind of theories are acceptable.

A third element to be emphasized is that a style of thought exists only as long as it is linked to a particular social group. To understand the existence of a style of thought is to analyse the social institutions behind it. This is particularly important since it helps to explain changes that may occur in the dominant thoughts of a society. The replacement of one way of knowing for another is not to be understood in terms of some specific truths that emerge, since they only take place within a certain style of thought. Rather, it ought to be seen in relation to the changes in the social actors who carry and reproduce that style of thought.

\subsection{Two Styles of Thought in Geology}

Émile Argand (1870-1940) was a Swiss geologist interested in history and philosophy. In 1922, he presented his ideas about the movements of the continents in a geological conference held in Brussels. In reviewing the arguments around the subject, he stated that some theories implied the fixation of the continents while others supposed great displacements. He argued that these were rather "attitudes", which he called fixism and mobilism (Argand 1924, 289; Krill 2014, 114). The notion of attitude he used is interesting because it implies that there is a previous willingness to accept a theory. Although he did not develop a definition of attitude, it supposes certain predisposition to accept or reject some kind of approaches. As we shall see, it is not only a will but rather a set of notions, practices and beliefs that shape certain predisposition towards a theory. Nevertheless, the terms fixism and mobilism seem suitable to describe those styles of thought.

At least until mid twentieth century, most biogeographers considered that the positions of the continents had been relatively stable over the time scales (Giller et al. 2004, 268). From time to time, the notion of lateral movement of the continents emerged, but it was always invariably ridiculed by the scientific establishment (Miller 1983, 18). Of course, fixists had to face some of the evidence that mobilists used in their favour. Such was the case of similarities of the fossils which existed in different continents. But fixists managed to explain that evidence preserving the principle of fixed continents. The botanist Joseph Hooker (1817-1911), in the mid nineteenth century, considered that once there was a whole extensive flora, which was broken up by geological and climatic causes. Still, Hooker believed that the continents were fixed and once connected by trans-oceanic land bridges (Giller et al. 2004, 268). The idea of trans-oceanic bridges became very popular as the explanation for the presence of similar fossils in different continents. It was widely

Footnote 10 (continued)

distinctive thought style develops as the communicative genre for a social unit [...] constituting itself'. In this sense, science has several thought styles (Douglas 1996, xii). 
accepted by fixists that there was a system of land bridges that had once linked all continents enabling plants and animals to move freely and, afterwards, all those bridges collapsed. Numerous bridges were proposed to have existed across oceans in the past, in different locations and with particular names. Africa and Brazil were supposed to be connected by a land bridge called Archhelenis, Europe and North America by Archatlantide, and so on (Gohau 1991, 191).

Another major issue was the existence of mountain ranges, whose genesis was explained by mobilists through the crush of continents. Of course, fixists had another way to explain that genesis. One of the most prominent advocates of the fixist style of thought was the geologist James Dwight Dana (1813-1895), who considered that the Earth was cooling and contracting from a previously molten state. This contraction would explain the great mountain ranges all around the world (Miller 1983, 18). The popular way of explaining the contraction theory was with the analogy of a baked apple coming out of the oven, with the corrugation of mountain ranges compared with the shrinking of the cooling apple skin over the reduced interior (Greene 2015, 253). In every case, for fixists, it was impossible to conceive that the continents could move horizontally, and they have other explanations for mobilists' arguments about the issue.

As both styles of thought have developed through the centuries, there is not just one theory that defines them. On the contrary, several authors with different theories have emerged within each current of thought. Consequently, a style of thought accounts for general aspects that can be traced in diverse theories or practices. For fixism, its object of study has remained in the same place since its creation. It tends to attribute continents changes over time to their own degradation: the collapse of land bridges, the loss of temperature, the sinking of heavy parts of the crust, among others.

On the other hand, mobilism imagines its object as something in permanent change whose continuous interactions redefine it every time. Fixists find it natural to see the same structure over time, and label as extravagant all theories whose object is continuously moving. For mobilists, the only fix element to be found is change. ${ }^{11}$ Both styles of thought coexisted for centuries providing a general background for the acceptance/rejection of the continental drift theory.

\subsection{Mobilism and Fixism Beyond Geology}

We can consider fixism and mobilism as two styles of thought not only because they imply two ways of reasoning which frames what to consider acceptable in the structure and development of the Earth and its continents but because they imply a way of reasoning that can also be found in other fields besides geology. Indeed, in order to speak of a style of thought, as argued by Harwood, one must account not only for differences between groups but also its presence in various instances of cultural activity (Harwood 1993, 9). In that sense, these differences shown between fixists and mobilists in relation to continents and the Earth structure can also be found in many other fields. One of the most notorious, of course, is the creation of species. There, we can identify fixists with creationists, who argue that species are

\footnotetext{
11 Evan Hopkins (1810-1867), an overlooked geologist that supported the horizontal displacement of continents, chose as epigraph of his 1844 book the following revealing John Playfair's quote: "Amid all the revolutions of the globe, the economy of Nature has been uniform, and her laws are the only things that have resisted the general movement. The rivers and the rocks, the seas and the continents, have been changed in all their parts; but the laws which direct those changes, and the rules to which they are subject, have remained invariably the same" (Hopkins 1844, i). See also Krill $(2014,21)$.
} 
fixed, that new species were only created by God; whereas mobilists can be identified with evolutionists. Interestingly, recent studies in science education have stressed the importance of teaching evolutionary theory jointly with continental drift and plate tectonics theories, as a way of promoting students' reflections in the same way of scientific thinking (Sousa 2016). On the other hand, evolution detractors usually assess continental drift to be as poorly established as evolution (Downie and Barron 2010, 144). Indeed, creationist perspectives tend to identify themselves with fixist style of thought (Morris 1978; Nevins 1976).

In social issues, similar differences can also be established for both styles of thought: social differences as expressions of fixed elements present in individuals, or as the expressions of a certain moment of social relations but subject to change.

The relation between some of these theories and religion is not surprising since they share some basic assumptions on fixism; the relation is mediated by the style of thought. Both fixism and many religions think in terms of essential attributes that cannot change considering, therefore, stable (or at most, degraded) elements in Earth since its creation. Fixists in geology explained the observed changes in the planet without damaging the doctrine of the act of Genesis, and that was achieved by interpreting Noah's flood as a kind of adjustment to the Creation. In 1681, the English cleric Thomas Burnet offered a cataclysmic account of the Deluge with geological overtones, which was then usually reproduced by fixists theories (Miller 1983, 11).

In a way, fixism could be described as a style of thought that relies on fixed and constant attributes and structures, while mobilism feels comfortable with more dynamic postulates. Hence, these styles served as models for thinking and reasoning about different types of subjects.

\section{What has Changed?}

Studies of continental drift debate notice that until the 1960s Wegener's theory was widely dismissed, but, after then, the vast majority of the geologist community accepted that continents moved horizontally. In order to explain such a shift, those studies usually look for the main cognitive changes that occurred inside the field and find out that new evidence of seismographic nature was provided. The conclusion they offer is that such evidence proved the theory correct and tipped the balance of support in its favour.

Particularly, the establishment of a seismograph network to monitor the compliance with the 1963 treaty banning above-ground testing of nuclear weapons and the ocean floor mapping provided, in the following years, useful data about magnetic patterns in the Pacific as well as earthquakes and volcanic activities (Kious and Tilling 1996). Volcanic activity may explain seafloor spreading. Subsequently, the plate tectonic theory emerged as a widely accepted theory. The Earth plates continually move, which explains the continental displacement and most of the Earth's seismic activity that occurs at the plate boundaries as they interact.

Much of the evidence about seafloor spreading was due to geologist Harry Hess, who published in 1962 his History of ocean basins. He argued that the Earth's crust moved laterally away from long, volcanically active oceanic ridges. Harry Hess's idea of seafloor spreading offered evidence in favour of a mechanism of drift, explaining how the continents could drift through the ocean floor (Le Grand and Homer 1988, 197; Šešelja and Weber 2012, 149).

The first obvious objection to be made is that the plate tectonic theory is not strictly the same as the continental drift theory put forward by Wegener, although, of course, 
both accept the idea of horizontal movements of the continents. Secondly, since Ortelius's considerations about continental drift in the sixteenth century, new evidence was always brought up by this kind of perspectives. Why, then, did it become accepted this time? These tales, then, suggest this was more than another piece of evidence, that is, an evidence of another kind, a sort of irrefutable evidence.

But it did not happen that fixists' supporters saw the new evidence and surrendered to it. Evidence is never enough to change ways of thinking.

In a 1964 Royal Society symposium devoted to continental drift, some prestigious scientists such as Gordon MacDonald, J. Lamar Worzel and sir Harold Jeffreys, still opposed to the theory and defied the new evidence (Frankel 2012, 148-232). Some scientists even rejected the continental drift theory after finding their own data which contradicted the most recent evidence (Solomon 2001, 105). In the following years, the widely recognized British geophysicist sir Harold Jeffreys complained "against the biased propaganda in favour of continental drift" (Jeffreys 1969, 706). According to Jeffreys, there was overwhelming evidence that showed how convection and continental drift were forbidden by the Earth's laws (Jeffreys 1969, 1970). In 1972, Paul S. Wesson collected 74 objections to continental drift and plate tectonics, in order to state that "the continents have almost certainly not moved with respect to each other" (Wesson 1972, 185).

In a relevant but overlooked survey to American geologists in the 1960s and 1970s, Nitecki et al. (1978) analysed the characteristics of both, those who supported and those who detracted the plate tectonic-continental drift theory. Astonishingly, those who had recently accepted the theory as well as those who fiercely opposed to it were equally unaware of the new literature (Nitecki et al. 1978, 662). Moreover, those who, in fact, were highly familiarized with the bulk of modern evidence had already accepted the theory prior to 1970. This observation is in accordance with Stewart's study, where he points out that "only a couple of scientists appeared to change their mind between earlier and later publications" (Stewart 1986, 269); and also with Solomon's remark about how "those who were predisposed towards drift [...] tended to accept seafloor spreading" while "those who were opposed to drift [...] tended to welcome arguments against drift" (Solomon 2001, 105). Evidence nourishes those who are already convinced.

Still, something changed the consensus among geologists as by the end of the 1970s, continental drift theory had a large number of adepts. Before 1961, only $22 \%$ of professional geologists surveyed accepted the continental drift theory; by 1977 that percentage was around 87\% (Nitecki et al. 1978, 661). If it was not just the new evidence, what was it?

Laudan and Laudan (1989) convincingly argued that there may be divergent standards for evaluating a theory, and that consensus may form when a theory becomes dominant. Here we are emphasizing the importance of broad sociological issues in shaping that dominance.

The notion of styles of thought as an analytical tool proves useful to give a broad interpretational frame for cultural issues. Mobilist style of thought had already triumphed in other scientific fields, like biology. Darwin, Wallace, and even Lamarck's evolutionist theories in the late nineteenth century had largely displaced creationist perspectives. And they can also be interpreted as a reflection of a broader social change in a way of thinking. As Levins and Lewontin argue, in a general sense Darwin translated into biology ideas of change that were already present in the intellectual milieu of his time:

The Darwinian theory of evolution is a quintessential product of the bourgeois intellectual revolution. [...] [I]t was a theory of change as opposed to stasis, part of the nineteenth-century commitment to change (Levins and Lewontin 1985, 3). 
But at the same time, styles of thought do not develop in a society as vague ether. They exist within social institutions. There are places, persons, jobs, where a thought style may flourish and reproduce or not. And that explains the differences in acceptance between scientific fields. The professional community of geologists was quite heterogeneous at the beginning of the twentieth century, with many of them working in the industry. But university teaching began to be occupied by mobilists, and that had a big influence on the formation of the future geologists (Nitecki et al. 1978, 663). A change in the profile of reproduction of styles of thought can also be deduced from the relationship between publications and acceptance of the theory. According to Stewart (1986, 271), "those scientists who published more articles were less likely to accept continental drift". That is in perfect consonance with Bourdieu's (1976) analysis of scientific field structure, in which he argued that those who accumulated a scientific capital within a paradigm are less likely to adopt revolutionary strategies since their symbolic capital makes sense within that paradigm. Most likely, new generations of geologists, educated under the teaching of mobilists geologists, accepted the theory just by inheriting the mobilist style of thought. That is, by considering "the relative independence of acceptance from the degree of familiarity with the literature, we might suppose that there was at some period—-perhaps during the mid-1960s — a "chain reaction' or other general shift in opinions toward the theory" (Nitecki et al. 1978, 664). This is, in fact, reinforced by Messeri's study about the age differences in the acceptance of the theory. Messeri shows that in the late 1960s the scientific community shifted, indeed, towards the acceptance of continental drift theory. But those who accepted the theory on those years were mainly young scientists (with few years from getting their last degree), that is, scientists who were just beginning their career (Messeri 1988, 104-106).

It's not that fixists changed their mind; instead, mobilists increased the number of young followers, probably by occupying university spaces.

\section{Discussion}

In this work, I have argued that both styles of thought, fixism and mobilism, coexisted through hundreds of years, always confronting their own evidence and interpretations. During most of that time, mobilism was a minority. In geology, only after the 1960s, mobilism reached a broad consensus, although fixists still exist as a minority (the existence of styles of thought implies that their relative incidence in society may change, but they do not disappear). ${ }^{12}$

\footnotetext{
12 Indeed, there is still a fixist style of thought in geology, and some of it appears in the New Concepts in Global Tectonics Group (Pratt 2006). Since 1996, this group of Earth scientists carry out periodical conferences and publishes their own journal with a dissident perspective: they argue that plate tectonics theory was developed in the 1960s by young inexperienced geologists with a simplistic view and that all existing data was just swept aside. Interestingly, this anti-continental drift group is linked with a religious movement, which is coherent with the essentialist aspects of fixism style of thought (see Exploring theosophy: The synthesis of science, religion and philosophy, at: http://www.davidpratt.info. Accessed 26 January 2019. Links between anti-continental drifts and religious positions may also be found at: http://www. icr.org/article/continental-drift-plate-tectonics-bible. Accessed 26 January 2019). A similar situation may be described for creationists, who found certain institutions within the United States that allow them to develop their ideas and reproduce them, despite the overwhelming consensus among the scientific community towards evolution.
} 
Although this questions the idea that scientists are pure rational decision makers, it does not necessarily imply a relativist approach that suggests that the dominance of either style of thought is equally arbitrary. By framing the notion of social empiricism, Solomon argues that individual scientists are prone to various cognitive biases and heuristics (Harker 2015, 128), and that "consensus depends not only on superior empirical success of one theory but also on the responsiveness of the social structure in which decisions are embedded" (Solomon 1994, 339). In a way, the existence of a minority of scientists nowadays who reject the mobilists' theory in geology can be compared with creationists denying evolution, or the Perth Group denying the connections between AIDS and HIV. The existence of a large consensus of scientists really matters, even if minority groups of scientists disagree. That consensus shows the real level of agreement within the scientific community, and it is naif to think that every consensus is absolute. As well as it is dangerous to make judgments by listening to some marginal scientists positions without considering the global subject situation in the scientific community. ${ }^{13}$ To understand that there are styles of thought underlying a theory acceptance does not underestimate either the theory or its evidence: it contradicts the belief that evidence by itself may lead to the acceptance of an idea, while cultural changes rely less on evidence than on social struggles for positions and opportunities to expand and reproduce those ideas. To be accepted, an idea must first become acceptable, and such a process may be slow because every style of thought has its own limits to what it considers acceptable. ${ }^{14}$

In the case of continental drift theories, it took almost 400 years until mobilist style of thought imposed itself over fixism. Further studies may contribute to this approach by examining in more detail the presence of these styles of thought in diverse social spaces (the confluence of different evolutionary theories with continental drift ideas-as it happened with Lamarck and Darwin, for instance-, serves as an example of a mobilist style of thought), and by deeply examining the changes in social institutions-such as universities-and their correlation with the acceptance of styles of thought. Indeed, this article approach states that it was not just one sort of evidence what convinced geologists of accepting mobilits' ideas, but rather the social growth of mobilists what influenced geologists' position about the continental drift debate.

Here it was argued that the way to deal with evidence depends on broad cultural and social phenomena, since no evidence by itself is enough to accept a theory. The evidence is not what defines something to be taken as truth or not. There is something beneath, a condition of possibility to all truth, and this is how acceptable it is for social groups. The acceptability of a statement does not depend on the amount of evidence it provides. There are theories which were accepted with very little evidence (Einstein's notion of gravitational waves, for instance, was proposed in 1915, but the evidence of their existence was found just by 2016; yet, during 100 years nobody really doubted of them); while others, such as Wegener, Taylor and many other authors since Ortelius had diverse evidence to support their theories but yet they were not seriously considered. Hence, the acceptability

\footnotetext{
13 The effects of the Perth Group, a group of dissident scientists, are an example of it. In 1999, the President of South Africa followed the Perth Group position and ended the provision of AZT (azidothymidine) in AIDS treatment. But the Perth Group, who denied links between AIDS and HIV and questioned the effectiveness of AZT, wasn't reflecting the large consensus in the scientific community on the matter (Weinel 2007).

14 In his study about the monopole controversy, Pickering (1981) stressed the importance of prior social agreements which consider certain concepts as socially acceptable. A fact needs to be first socially acceptable, for only then can it be socially accepted.
} 
of a statement depends on the community prior beliefs. When postulating a new theory, if it fits within the previous beliefs of a community, it will be well received. On the contrary, if it is not considered acceptable, it will be rejected no matter how much evidence it may provide.

\section{Conclusion}

Continental drift controversy has been hosting many rationalist approaches. It has been argued that the emergence of paleomagnetic evidence proved mobilists' theory more consistent, based on more solid evidence, and with a much broader problem-solving effectiveness. Hence, rationalist approaches to the case suggest that the causes for fixists' defeat should be found within those epistemological aspects of the controversy. Although those differences between fixists' and mobilists' theories certainly do exist, the controversy can hardly be explained without considering broader sociological aspects too. In that regard, the following aspects of the controversy have remained largely absent from rationalist approaches, and the styles of thought perspective provided in this article has shed some light over them:

1. Measuring the impact of the paleomagnetic evidence in the closure of the controversy: Scientists standing both for and against continental drift theory in the 1960s and 1970s were largely not familiarized with paleomagnetic evidence, so it can hardly explain the closure of the controversy. Moreover, many scientists challenged that evidence. Changes in the dominant style of thought (e.g. through alterations in force relations within educational institutions) may contribute to explain social aspects of the controversy closure.

2. Ignoring mobilists contributions on the subject for hundreds of years: Neglecting authors who have been sustaining mobilists arguments and evidence concerning continental drift theory is not merely a curious phenomenon or a problem of communication of ideas, but part of the same conflict between styles of thought. Ignoring challenging positions is a possible reaction of a dominant style of thought against an anomaly, as well as questioning its validity, exposing its problems or offering other explanations against it.

3. Continuing expressions of fixism even after the closure of the controversy: Although there is a clear minority within scientific community now, there are still some researchers that oppose continental drift theory, and their view can be related to cultural patterns expressed in a style of thought.

Against rationalist approaches, Feyerabend argues that theory choice is not rational because the moves that would make it rational rest on assumptions of another kind: first the parties have to decide what evidence they will accept as refuting evidence; then, the "rational procedure" of refutation can start (Feyerabend 1979, 98). Although social studies of science have developed in many ways from Feyerabend's work, where the analysis of the social assumptions of theories have been central, the specific case of continental drift theory seems to have been hosting merely rationalist approaches. By using the concept of styles of thought, I have intended to show that continental drift controversy can also be useful for the study of social and cultural backgrounds which condition the acceptance of a scientific theory. Further studies on the structure and changes in the scientific community of geologists would enrich these approaches. 
Acknowledgements Open access funding provided by Max Planck Society. The author wishes to thanks Max Planck Institute for the History of Science for the visiting scholar fellowship received, and for the stimulating and supportive atmosphere provided. Special thanks are given to Jonathan Harwood for his helpful observations on the article's first draft, and to the editor and reviewers for their very constructive comments.

Open Access This article is distributed under the terms of the Creative Commons Attribution 4.0 International License (http://creativecommons.org/licenses/by/4.0/), which permits unrestricted use, distribution, and reproduction in any medium, provided you give appropriate credit to the original author(s) and the source, provide a link to the Creative Commons license, and indicate if changes were made.

\section{References}

Argand, É. (1924). La tectonique de l'Asie. In Congrès géologique international (XIII session, Belgique 1922) (pp. 171-372). Liège: Imprimerie Vaillant-Carmanne.

Barnes, B., \& Bloor, D. (1982). Relativism, rationalism and the sociology of knowledge. In M. Hollis, \& S. Lukes (Eds.), Rationality and relativism (pp. 21-47). Cambridge: MIT Press.

Bloor, D. (1976). Knowledge and social imagery. London: Routledge \& Kegan Paul.

Bourdieu, P. (1976). Le champ scientifique. Actes de la recherche en sciences sociales, 2(2-3), 88-104.

Brannigan, A. (1981). The social basis of scientific discoveries. New York: Cambridge University Press.

Carozzi, A. V. (1970). New historical data on the origin of the theory of continental drift. Geological Society of America Bulletin, 81(1), 283-286.

Carozzi, A. V. (1983). Heinrich Wettstein (1880): A swiss forerunner of global mobilism. Earth Sciences History, 2(1), 41-47.

Collins, H. M. (1981). What is TRASP? The radical programme as a methodological imperative. Philosophy of the Social Sciences, 11(2), 215-224.

Collins, H. M., \& Pinch, T. (1998). The golem: What you should know about science. Cambridge: Cambridge University Press.

Crombie, A. C. (1994). Styles of scientific thinking in the European tradition: The history of argument and explanation especially in the mathematical and biomedical sciences and arts. London: Duckworth.

Douglas, M. (1996). Thought styles. London: Sage Publications.

Downie, J. R., \& Barron, N. J. (2010). Evolution and religion: Attitudes of Scottish first year biology and medical students to the teaching of evolutionary biology. Journal of Biological Education, 34(3), 139-146.

Du Toit, A. L. [1937] (1957). Our wandering continents: An hypothesis of continental drifting. London: Oliver and Boyd.

Feyerabend, P. (1979). Dialogue on method. In G. Radnitzky, \& G. Andersson (Eds.), The structure and development of science (pp. 63-131). Dordrecht: Reidel Publishing Company.

Fleck, L. [1935] (1979). Genesis and development of a scientific fact. Chicago: University of Chicago Press.

Frankel, H. R. (1979). The reception and acceptance of continental drift theory as a rational episode in the history of science. In S. H. Mauskopf (Ed.), The reception of unconventional science: AAAS selected symposium (pp. 51-89). Boulder: Westview Press.

Frankel, H. R. (2012). The continental drift controversy. Volume 4: Evolution into plate tectonics. Cambridge: Cambridge University Press.

Georgi, J. (1962). Memories of Alfred Wegener. In S. K. Runcorn (Ed.), Continental drift (pp. 309-324). New York: Academic Press.

Giedymin, J. (1986). Polish philosophy in the inter-war period and Ludwik Fleck's theory of thought-styles and thought-collectives. In R. S. Cohen, \& T. Schnelle (Eds.), Cognition and fact: Materials on Ludwik Fleck (pp. 179-215). Dordrecht: Reidel Publishing Company.

Giere, R. (1988). Explaining science: A cognitive approach. Chicago: University of Chicago Press.

Giller, P. S., Myers, A. A., \& Riddle, B. R. (2004). Earth history, variance, and dispersal. In M. V. Lomolino, D. F. Sax, \& J. H. Brown (Eds.), Foundations of biogeography: Classic papers with commentaries (pp. 267-276). Chicago: The University of Chicago Press.

Gohau, G. (1991). A history of geology. New Brunswick: Rutgers University Press.

Grand, L., \& Homer, E. (1988). Drifting continents and shifting theories. Cambridge: Cambridge University Press.

Greene, M. T. (2015). Alfred Wegener: Science, exploration and the theory of continental drift. Baltimore: Johns Hopkins University Press. 
Hacking, I. (1982). Language, truth and reason. In M. Hollis, \& S. Lukes (Eds.), Rationality and relativism (pp. 48-66). Cambridge: MIT Press.

Hacking, I. (1992). 'Style' for historians and philosophers. Studies in History and Philosophy of Science, 23(1), 1-20.

Hacking, I. (1999). The social construction of what? Cambridge, MA: Harvard University Press.

Hallam, A. (1975). Alfred Wegener and the hypothesis of continental drift. Scientific American, 232(2), 88-97.

Hallam, A. (1983). Great geological controversies. New York: Oxford University Press.

Harker, D. (2015). Creating scientific controversies. Cambridge: Cambridge University Press.

Harwood, J. (1986). Ludwik Fleck and the sociology of knowledge. Social Studies of Science, 16(1), $173-187$.

Harwood, J. (1993). Styles of scientific thought: The German genetics community, 1900-1933. London: The University of Chicago Press.

Hopkins, E. (1844). On the connexion of geology with terrestrial magnetism: Showing the general polarity of matter, the meridional structure of the crystalline rocks, their transitions, movements and dislocations, including the sedimentary rocks, the laws regulating the distribution of metalliferous deposits, and other magnetic phenomena. London: Richard and John Edward Taylor.

Hopwood, N. (1994). Genetics in the mandarin style. Studies in History and Philosophy of Science, 25(2), $237-250$.

Jeffreys, H. (1969). Continental drift. Nature, 222(5194), 706.

Jeffreys, H. (1970). Imperfections of elasticity and continental drift. Nature, 225(5237), 1007-1008.

Kasbeer, T. (1973). Bibliography of continental drift and plate tectonics (Geological Society of America, special paper 142). Boulder, CO: The Geological Society of America.

Kious, W. J., \& Tilling, R. I. (1996). This dynamic earth: The story of plate tectonics. Washington, DC: U.S. Government Printing Office.

Knorr-Cetina, K. (2007). Culture in global knowledge societies: Knowledge cultures and epistemic cultures. Interdisciplinary Science Reviews, 32(4), 361-375.

Krill, A. (2014). Not getting the drift: A hard look at the early history of plate-tectonic ideas. http://folk. ntnu.no/krill/krilldrift1.pdf. Accessed 27 January 2019.

Lane, A. C. (1944). Frank Bursley Taylor (1860-1938). Proceedings of the American Academy of Arts and Sciences, 75(6), 176-178.

Laudan, R. (1983). Redefinitions of a discipline: Histories of geology and geological history. In L. Graham, W. Lepenies, \& P. Weingart (Eds.), Functions and uses of disciplinary histories (pp. 79-104). Dordrecht: Reidel Publishing Company.

Laudan, R. (1985). Frank Bursley Taylor's theory of continental drift. Earth Sciences History, 4(2), 118-121.

Laudan, R. (1987). The rationality of entertainment and pursuit. In C. P. Jopseph, \& P. Marcello (Eds.), Rational changes in science: Essays on scientific reasoning, (pp. 203-220). Dodrecht: D. Reidel Publishing Co.

Laudan, R., \& Laudan, L. (1989). Dominance and the disunity of method: Solving the problems of innovation and consensus. Philosophy of Science, 56(2), 221-237.

Levins, R., \& Lewontin, R. (1985). The dialectical biologist. Cambridge, MA: Harvard University Press.

Löwy, I. (1988). Ludwik Fleck on the social construction of medical knowledge. Sociology of Health \& Illness, 10(2), 133-155.

Maienschein, J. (1991). Epistemic styles in German and American embryology. Science in Context, 4(2), 407-427.

Mannheim, K. [1925] (1986). Conservatism: A contribution to the sociology of knowledge. London: Routledge \& Kegan Paul.

Martínez, M. L. (2016). Foucauldian imprints in the early works of Ian Hacking. International Studies in the Philosophy of Science, 30(1), 69-84.

Merton, R. K. (1961). Singletons and multiples in scientific discovery: A chapter in the sociology of science. Proceedings of the American Philosophical Society, 105(5), 470-486.

Messeri, P. (1988). Age differences in the reception of new scientific theories: The case of plate tectonics theory. Social Studies of Science, 18(1), 91-112.

Miller, R. (1983). Continents in collision. Amsterdam: Time-Life.

Morris, H. M. (1978). The day-age theory revisited. Acts \& Facts, 7(1). Available at: http://www.icr.org/ article/137/. Accessed 27 January 2019.

Mößner, N. (2011). Thought styles and paradigms: A comparative study of Ludwik Fleck and Thomas S. Kuhn. Studies in History and Philosophy of Science, 42(2), 362-371.

Muir Wood, R. (1980). Coming apart at the seams. New Scientist, 85(1191), 252-254.

Nelson, R. D. (1992). The sociology of styles of thought. British Journal of Sociology, 43(1), 25-54. 
Nelson, A. (1994). How could scientific facts be socially constructed? Studies in History and Philosophy of Science, 25(4), 535-547.

Nevers, P., Hasse, R., Hohlfeld, R., \& Zimmerli, W. (2001). Mediating between plant science and plant breeding: The role of research-technology. In B. Joerges, \& T. Shinn (Eds.), Instrumentation: Between science, state and industry (pp. 97-118). Dordrecht: Kluwer Academic Publishers.

Nevins, S. E. (1976). Continental drift, plate tectonics, and the bible. Acts \& Facts, 5(2). Available at: http:// www.icr.org/article/continental-drift-plate-tectonics-bible/. Accessed 27 January 2019.

Newman, R. P. (1995). American intransigence: The rejection of continental drift in the great debates of the 1920s. Earth Sciences History, 14(1), 62-83.

Nield, T. (2015). The continental conundrum. Nature, 526(7572), 192-193.

Nitecki, M. H., Lemke, J. L., Pullman, H. W., \& Johnson, M. E. (1978). Acceptance of plate tectonic theory by geologists. Geology, 6(11), 661-664.

Oreskes, N. (1999). The rejection of continental drift: Theory and method in American earth science. New York: Oxford University Press.

Oreskes, N. (2013). How plate tectonics clicked. Nature, 501(7465), 27-29.

Pickering, W. H. (1907). The place of origin of the Moon: The volcanic problem. Popular Astronomy, 15, 274-287.

Pickering, A. (1981). Constraints on controversy: The case of the magnetic monopole. Social Studies of Science, 11(1), 63-93.

Powell, J. L. (2015). Four revolutions in the earth sciences: From heresy to truth. New York: Columbia University Press.

Pratt, D. (2006). Organized opposition to plate tectonics: The new concepts in global tectonics group. Journal of Scientific Exploration, 20(1), 97-104.

Romm, J. (1994). A new forerunner for continental drift. Nature, 367(6462), 407-408.

Rupke, N. A. (1970). Continental drift before 1900. Nature, 227(5256), 349-350.

Rupke, N. A. (1996). Eurocentric ideology of continental drift. History of Science, 34(105), 251-272.

Scalera, G. (2003). Roberto Mantovani: An Italian defender of the continental drift and planetary expansion. In G. Scalera, \& K.-H. Jacob (Eds.), Why expanding earth? (pp. 71-74). Rome: INGV.

Sciortino, L. (2016). Styles of reasoning, human forms of life, and relativism. International Studies in the Philosophy of Science, 30(2), 165-184.

Šešelja, D., \& Weber, E. (2012). Rationality and irrationality in the history of continental drift. Studies in History and Philosophy of Science Part A, 43(1), 147-159.

Snider-Pellegrini, A. (1858). La création et ses mystères dévoilés. Paris: Franck-Dentu.

Solomon, M. (1994). Social empiricism. Noûs, 28(3), 325-343.

Solomon, M. (2001). Social empiricism. Cambridge, MA: The MIT Press.

Sousa, C. (2016). Bridging Darwin's origin of species and Wegener's origin of continents and oceans: Using biogeography, phylogeny, geology and interactive learning. The American Biology Teacher, 78(1), 24-33.

Stewart, J. A. (1986). Drifting continents and colliding interests: A quantitative application of the interests perspective. Social Studies of Science, 16(2), 261-279.

Stewart, J. A. (1990). Drifting continents and colliding paradigms: Perspectives on the geoscience revolution. Bloomington: Indiana University Press.

Stigler, S. M. (1999). Statistics on the table: The history of statistical concepts and methods. Cambridge, MA: Harvard University Press.

Taylor, F. B. (1910). Bearing of the tertiary mountain belt on the origin of the Earth's plan. Bulletin of the Geological Society of America, 21(1), 179-226.

Thagard, P. (1992). Conceptual revolutions. Princeton, NJ: Princeton University Press.

Vicedo, M. (1995). Scientific styles: Toward some common ground in the history, philosophy, and sociology of science. Perspectives on Science, 3(2), 231-254.

Wegener, A. [1915] (1929). The origin of continents and oceans. London: Methuen.

Weinel, M. (2007). Primary source knowledge and technical decision-making: Mbeki and the AZT debate. Studies in History and Philosophy of Science Part A, 38(4), 748-760.

Wesson, P. S. (1972). Objections to continental drift and plate tectonics. The Journal of Geology, 80(2), $185-197$.

Wilson, J. Tuzo. (1968). Static or mobile Earth: The current scientific revolution. Proceedings of the American Philosophical Society, 112(5), 309-320. 